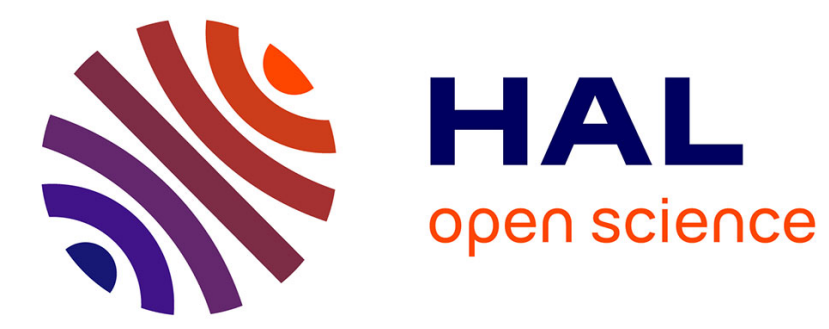

\title{
LAIT PASTEURISÉ - LAIT STÉRILISÉ
}

G. Thieulin

\section{To cite this version:}

G. Thieulin. LAIT PASTEURISÉ - LAIT STÉRILISÉ. Le Lait, 1956, 36 (353_354), pp.155-159. hal-00928160

\section{HAL Id: hal-00928160 https://hal.science/hal-00928160}

Submitted on 1 Jan 1956

HAL is a multi-disciplinary open access archive for the deposit and dissemination of scientific research documents, whether they are published or not. The documents may come from teaching and research institutions in France or abroad, or from public or private research centers.
L'archive ouverte pluridisciplinaire HAL, est destinée au dépôt et à la diffusion de documents scientifiques de niveau recherche, publiés ou non, émanant des établissements d'enseignement et de recherche français ou étrangers, des laboratoires publics ou privés. 
du type Streptococcus lactis et Bacterium casei. Le Lait, 13, 677-686, 1933.

[7] K. Singh et H. Laxminarayana. Studies on the growth of starter organisms in abnormal milk. Indian Journal Dairy Sci., 1, 78-86, 1948.

[8] J. Czulak et J. Meanwell. Seasonal variation in cheese starter activity. Proc. Soc., appl. Pact., 14, 1-6, 1951.

[9] G.-R. JAGo. Factors influencing the lactic acid-producing properties of streptococci used in the manufacture of Cheddar cheese. I. Observations relating inhibitory and stimulatory phenomena. Journal Dairy Res., 21, 111-121, 1954.

[10] M.-E. TyLer et H.-H. Weiser. Factors affecting Swiss cheese starter activity. Effect of heat-treatment and source of milk. Journal Dairy Sci., 25, 939-948, 1942.

[11] E. M. Foster. The effect of heat on milk as a culture medium for lactic acid bacteria. Journal Dairy Sci,35, 988-997, 1952.

[12] J.-E. AUCLAIR. Stimulation of certain bacteria by raw milk. Nature, 173, 491, 1954.

[13] J.-E. Auclair et A. Portmann. Un facteur de croissance pour Lactobacillus lactis, formé au cours du chauffage du lait à l'autoclave. C. R. Acad.Sc., 238, 2463-2465, 1954.

[14] P. Ritrter. Die Disposition der Milch. Landw. Jahrbuch der Schweiz, $63,595-686,1949$.

\section{LAIT PASTEURISÉ - LAIT STÉRILISÉ}

\section{par \\ G. THIEULIN}

Dans l'intérêt primordial de la santé publique et, dans celui, également important, sur le plan social et sur le plan économique, de la production agricole, il est désirable d'accroître considérablement la consommation du lait.

Ce lait doit évidemment être sain et nutritif.

Mais il doit également posséder les qualités gustatives permettant précisément d'en favoriser la consommation.

Sécurité biologique, valeur diététique, qualités organoleptiques : telles sont les propriétés d'un lait officiellement recommandable.

Production satisfaisante, pasteurisation rationnelle, paiement selon la qualité totale : tels sont les moyens de l'obtenir.

Par sécurité biologique, nous voulons entendre "absence de tout danger ", mais pas nécessairement " produit stérile ". Il convient certes de redouter les germes pathogènes, et plus généralement encore, l'action pathogène, mais il nous paraît dangereux d'afficher, par aveuglement, une crainte uniforme du microbe.

L'aliment, en particulier le lait, stérilisé, n'atteint-il pas ce 
stade inutile, au-delà du nécessaire, en contrepartie d'une diminution dé sa valeur nutritive initiale?

Le lait de vache, chauffé, est plus digestible pour l'homme, que le même lait cru, mais, au-delà d'un certain seuil, de précieux composants biochimiques sont altérés.

Recherchons done un juste milieu.

Les qualités organoleptiques influencent directement le consommateur. La saveur franche, fraîche et douce du lait, en rend la dégustation agréable.

L'adulte, sauf exception, ne recherche pas le gôtt de cuit. Sans doute, le peu de succès remporté à Paris depuis un an par le lait stérilisé, en est-il un témoignage direct (1). L'enfant a été rapidement du même avis. Doit-on rappeler que la substitution du lait "stérilisé" au lait "pasteurisé", dans les distributions faites aux enfants des écoles, a provoqué rapidement, tout au moins dans le département de la Seine, une désaffection croissante jusqu'à atteindre 60 à $65 \%$ des effectifs. Belle propagande, en vérité !

Et l'on a décidé de masquer le goût désagréable du lait cuit, par une aromatisation, en profitant de l'occasion pour remplacer le lait normal par du lait écrémé, pudiquement désigné d'ailleurs, par l'expression " à $0 \%$ de M. G. ", sans doute pour mieux renseigner le consommateur !

L’objectif, fort louable, et d'intérêt général, avait été primitivement de fournir un supplément alimentaire important aux enfants et, en les habituant du même coup à boire du lait, d'agrandir de façon durable, le cercle des amateurs du précieux liquide.

L'opération actuellement réalisée procurera-t-elle, autrement que de façon très particulière, et peut être même provisoire, les résultats escomptés?

Par ailleurs, une campagne est amorcée en divers points, en vue de l'amélioration réelle de la production du lait.

Le corollaire en est évidemment le paiement du lait à la qualité totale, pour récompenser les efforts méritoires.

Mais il faudrait alors renseigner le public et lui faire admettre, après que les Pouvoirs publics l'auront eux-mêmes admis, que le lait, comme d'autres denrées, n'est pas une marchandise uniforme et encore moins quelconque. Là, se situe l'essentiel du problème.

Ainsi, au lieu d'un programme de répression, inefficace, et qui ne trompe d'ailleurs personne, pourrait être mis sur pied un plan d'ensemble, 'basé sur la prévention, et dans lequel la profession laitière, organisée, consciente de ses responsabilités et soucieuse

(1) Pour 1.100.000 litres de lait par jour, en 1955 : lait oru, 2,72\% ; lait pasteurisé, $93,72 \%$; lait stérilisé, $3,56 \%$. 
de ses légitimes intérêts, jouerait un rôle essentiel sous la garantie des Services d'hygiène.

En attendant que le bon sens l'emporte sur des théories partisanes ou égoïstes, nous avons cru devoir présenter à nos lecteurs, deux documents : le premier est un rappel sommaire dédié aux détracteurs de la pasteurisation ; le second est une importante étude.

Quelques mots en guise de conclusion.

Les Hygiénistes sont fondés à exiger que la pasteurisation ne réalise pas uniquement une prolongation de la vie commerciale du lait et devienne, dans tous les cas, une opération portant garantie sanitaire; une telle pasteurisation, rationnelle, devant comporter un chauffage, le moins important possible, d'un lait cru correctement récolté et rapidement transporté; le lait pasteurisé étant ensuite protégé contre toute recontamination.

A la suite de déclarations aux assises fragiles, un mouvement a été déclenché contre cette pasteurisation, en fạveur d'une stérilisation "commerciale ».

Dans ces conditions, il serait admis de ne pas exiger de cette dernière, ce que l'on reprochait à la première de ne pas réaliser !

Rappelons donc que, en ce qui concerne le lait de consommation en nature :

"Une pasteurisation bien faite apporte autant de sécurité qu'une stérilisation bien faite ", et que : "Un lait mal stérilisé ne présente pas plus de garantie qu'un lait mal pasteurisé ".

Nous pourrions même aller beaucoup plus loin (1) en énonçant de sérieux arguments.

Mais voici les deux documents annoncés.

\section{I. - La pasteurisation détruit le bacille de Kock dans le lait}

Nous avons souligné les travaux antérieurs, qui furent entrepris dans ce domaine sur une vaste échelle par les autorités de la Santé publique américaine, dans le but de savoir, d'une manière certaine, si ce lait pasteurisé par la technique H.T.S.T. (High temperatureshort time, c'est-à-dire pasteurisation haute et brève) était sans danger pour la consommation humaine.

Utilisant le bacille tuberculeux comme organisme-test dans la comparaison avec le lait cru, elles obtinrent la preuve - et l'on peut être certain que les tests furent conduits avec sévérité - que,

(1) G. Thieulin. Le problème du lait hygiénique, La Presse médicale, 1955, 63, n० 28, 583. - L'hygiène du lait de consommation. L'Action laitière, numéro spécial, octobre 1955 .

(2) Extrait de : "Cronshaw. Dairy Information, 1947. (Edition : Dairy Ind. Ltd. 24, Bride Lane, Fleet Street, London, EC 4) 
dans une installation correctement conduite, de tels organismes (B. K.) furent complètement détruits et que le lait était effectivement sain pour la consommation humaine. Les autorités ont procédé immédiatement à la reconnaissance et à l'approbation officielles du procédé sous la forme d'ordonnances publiées en 1933, et dans

RÉSULTATS RASSEMBLÉS CONCERNANT LA DESTRUCTION EFFECTIVE DU, BACILLE TUBERGULEUX DANS DES INSTALLATIONS DE PASTEURISATION

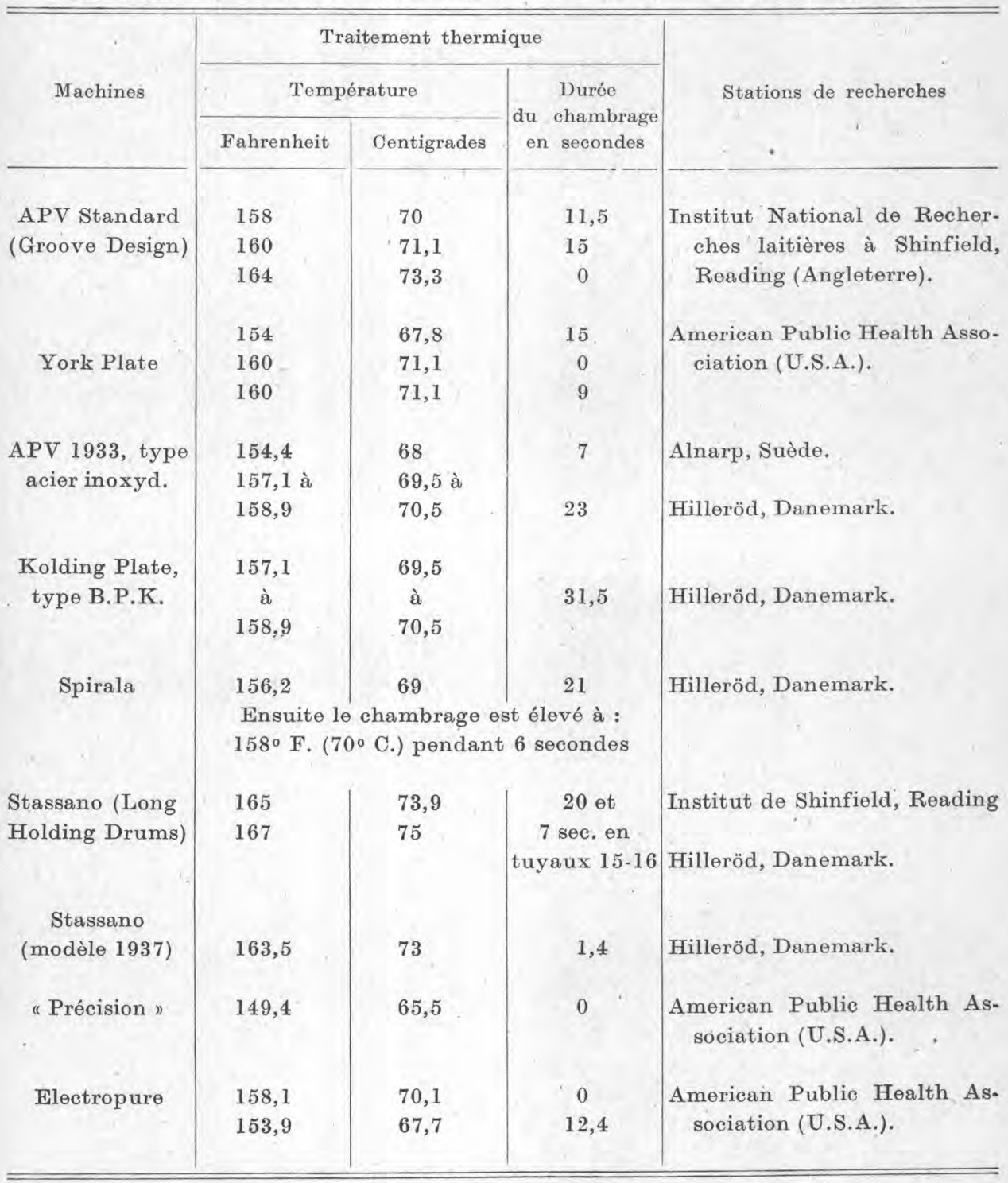


toutes les éditions successives du "Milk Ordinance and Code» (ordonnance et Code du lait) du Service de la Santé publique des Etats-Unis. Huit ans plus tard, en juillet 1941, une confiance suffisante ayant été inspirée en Grande-Bretagne par l'expérience accumulée dans les installations américaines et par les recherches du N.I.R.D. (Institut National de Recherches laitières) à l'Université de Reading, le Ministre de la Santé put y donner suite.

Il est parfaitement logique et raisonnable que les bactériologistes et autorités sanitaires aient adopté le projet d'orienter tout d'abord leur attention vers les résultats des entreprises commerciales touchant les effets destructeurs de la pasteurisation vis-à-vis des germes pathogènes les plus résistants à la chaleur plutôt que de se tourner vers des recherches pures de laboratoire. La législation doit être basée sur les résultats obtenus dans les conditions réelles de la pratique quotidienne et non pas uniquement sur les conditions simplifiées et plus ou moins idéales dans lesquelles les expériences de laboratoire sont conduites.

Les résultats de divers tests de contrôle des activités industrielles concernant la destruction du bacille tuberculeux dans le lait furent présentés par Miss Hiscox (de l'Institut de Recherches laitières de Reading) à une réunion du groupe de l'alimentation, le 12 janvier 1944. Quelques-uns des résultats qu'elle a donnés figurent dans le tableau ci-dessus.

Ces tests ne se proposent pas d'établir des combinaisons tempstempérature qui seraient juste suffisantes pour une destruction totale du bacille tuberculeux. Leur but était de prouver que les temps-températures auxquels les usines opéraient étaient suffisants pour assurer la destruction de tous les bacilles tubérculeux. Il a été utilisé à la fois des laits infectés artificiellement et des laits infectés naturellement. Matтick conclut d'une manière définitive (Med. Officer, 139, t. LXI, 1939) :

"Les bacilles tuberculeux sont tués après chauffage à $158^{\circ} 5 \mathrm{~F}$.

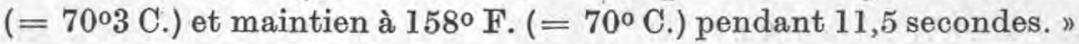

On peut ainsi voir que $162^{\circ} \mathrm{F}$. (7202 C.) pendant 15 secondes, donnent une bonne marge de sécurité, et l'on a adopté la combinaison suivante : $72^{\circ}-16$ secondes. 